\section{Treatment planning the endodontic-implant interface}

W. P. Saunders ${ }^{1}$

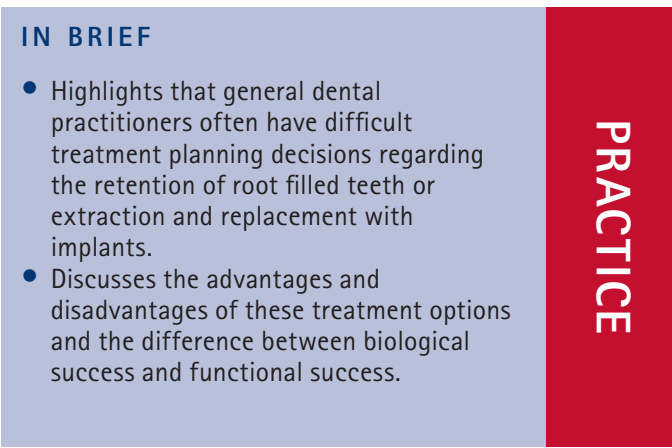

\begin{abstract}
One of the most challenging treatment planning decisions in restorative dentistry is the retention of a root filled tooth or its extraction and replacement with an implant. Making an informed judgement relies upon not only clinical experience and expertise but also interpretation of the published clinical evidence. In the last few years, more robust data and closer scrutiny of the evidence has helped to understand the advantages and disadvantages of each of these treatment modalities. The purpose of this paper is to provide a narrative review of some of the factors that may influence treatment planning for root canal treated teeth and indications for whether these teeth would be better replaced by an implant. From the evidence presented it is clear that both treatments have a place in contemporary restorative dental treatment and that survival for both root filled teeth and implants are similar. Unsurprisingly, both these treatment choices require high standards of clinical expertise and careful planning to ensure the best outcome.
\end{abstract}

\section{INTRODUCTION}

The purpose of both root canal treatment and implant placement is to restore masticatory function for the patient, and, in some cases, allow an improvement in aesthetics. The way this is achieved is fundamentally different and this has led to difficulties in interpretation of the role of each of these treatments. Root canal treatment, including non-surgical treatment, retreatment and surgical retreatment, is intended to retain the tooth as a functioning unit of the dentition while the implant replaces missing teeth. It can be argued that these treatments are merely a continuum of care for a specific tooth. The aetiology of irreversible dental pulp disease is infection, most usually from dental caries or, less commonly, trauma. There are then progressive changes through the root canal system resulting in an inflammatory response in the periradicular tissues of the tooth. Thus, in the vast majority of cases root canal treatment involves the elimination of infection and provides an environment to allow healing of the periradicular tissues. Should initial root canal treatment fail then there are opportunities to undertake retreatment

'Emeritus Professor of Endodontology, School of Dentistry, University of Dundee, Park Place, Dundee, DD1 4HN Correspondence to: Professor W. P. Saunders

Email:w.p.saunders@dundee.ac.uk

\section{Refereed Paper}

Accepted 12 December 2013

DOI: $10.1038 /$ sj.bdj.2014.202

${ }^{\circledR}$ British Dental Journal 2014; 216: 325-330 either non-surgically or surgically. If these treatments are not successful then there is an option to place an implant. By contrast, the implant is placed in bone where there is an absence of disease. This difference in the initial health state has meant that interpretation of success and failure of the two treatments has been disparate.

There are many factors that have to be taken into account when deciding to undertake root canal treatment for a tooth or extract and replace with an osseointegrated implant. These can be divided into local and systemic factors. Local factors regarding the tooth include the amount of coronal breakdown and restorability, the presence of periodontal disease, occlusal considerations and the quality and quantity of supporting bone. Systemic factors include general health, including conditions such as diabetes, prescribed treatment and medication (eg radiation, bisphosphonates) and habits such as smoking. In addition, the experience and proficiency of the practitioner play an important part in both the decision taken and the practicalities of the treatment. Of course judgements are best made by referring to the evidence base such as it is and interpreting that evidence in an unbiased way. The latter is sometimes difficult to do especially if the science is poor or inadequate. There are now a number of systematic reviews and meta-analyses regarding these treatments and they provide information that will inform clinical judgement. Before considering some of these factors it is clear that some indication of the outcome of the two modalities must be discussed.

\section{TREATMENT OUTCOMES}

Whilst outcome of root canal treatment has been based upon the success of the treatment as manifested by healing, this has not been the case with implant studies where survival rates tend to be measured. This dilemma has been highlighted by Iqbal and Kim. ${ }^{1}$ They considered that although criteria for clinical studies of implants had been produced, ${ }^{2,3}$ these were not always used, many studies using survival data only. In addition, many of the outcome studies in endodontics are related to treatment carried out in general dental practice while the treatment assessed in implants studies are performed by specialists.

\section{ROOT CANAL TREATMENT}

Strindberg ${ }^{4}$ was one of the first to define success in root canal treatment as an asymptomatic tooth with normal periodontal architecture at the periapex, bony infill and the absence of infection. These criteria have been applied and modified over the years. ${ }^{5-7}$ These are relatively strict criteria especially in relation to the presence of apical bone loss and do not take account of a symptomless root filled tooth remaining in function despite incomplete healing of the surrounding hard tissue. It has been shown that monitoring such teeth radiographically ( $n=420$, median time six years) resulted 
in maintenance of the status quo in $94.8 \%$ of cases, healing in $2.4 \%$ and failure in $2.8 \%$. If there was no or limited radiological evidence of periapical pathology and there were no symptoms, further complications were evident in a small number of cases. ${ }^{8}$

There have been many outcome studies of both non-surgical and surgical root canal treatment and these have been analysed through systematic reviews and meta-analyses.

\section{Non-surgical root canal treatment}

The excellent detailed reviews of both primary and secondary(non-surgical retreatment) root canal treatment by $\mathrm{Ng}$ et $a l .{ }^{9-11}$ provide a clear indication of success rates for these clinical procedures. They analysed 63 primary root canal treatment studies that matched the inclusion criteria and the success rate varied between $68 \%$ and $85 \%$ when strict criteria were used. They noted that 24 factors had been investigated in these studies but there was considerable heterogeneity in the estimate of pooled success rates. Disappointingly, they found no improvement in success rates in the five decades studied. In a second paper $\mathrm{Ng}$ et al..$^{10}$ found that four factors improved the outcome of primary treatment: pre-operative absence of a periapical radiolucency, a root filling with no voids, root filling to within $2 \mathrm{~mm}$ of the radiographic apex and a satisfactory coronal restoration. The pooled weighted success rate for the 17 studies included for secondary non-surgical root canal treatment was $76.7 \%$ (complete healing) and 77.2\% (incomplete healing). ${ }^{11}$ Significant prognostic factors included the presence of a pre-operative periapical lesion, the apical extent of the root filling and the quality of the coronal restoration. The authors stress that the quality of evidence is not as robust as it should be.

From this data it seems that despite the developments of new techniques for preparation and irrigation, success rates have not improved markedly and this was confirmed by a study comparing 'classic' endodontic techniques with more contemporary practices. ${ }^{12}$ It found that the survival rate for 459 teeth in the classic group was $98 \%$ over a mean period of 75.7 months, while the survival rate for the 525 teeth in the contemporary group was 96\% over 34 months.

$\mathrm{Ng}$ et al. ${ }^{13,14}$ embarked upon a prospective study of primary and secondary root canal treatment. This thorough study examined 1,170 roots for primary treatment and 1,314 roots for secondary treatment. Complete healing was noted in $83 \%$ of cases after primary root canal treatment and $80 \%$ after root canal retreatment. They found that ten factors had an effect on both treatments.

\section{Surgical root canal treatment}

In the last 20 years surgical root canal treatment has changed immeasurably with the use of micro surgical techniques and bioactive and biocompatible rootend filling materials. ${ }^{15-18}$ Predictable regeneration of the periapical tissues is now possible. Setzer et al. ${ }^{19,20}$ undertook a meta-analysis of the literature regarding the outcome of endodontic surgery. The use of microsurgical techniques resulted in a $94 \%$ success rate compared with 59\% for traditional surgical methods. The use of magnification, using either an operating microscope or an endoscope, resulted in a success rate of $94 \%$, compared to $88 \%$ with a microsurgical technique and no magnification or loupes only. A more recent meta-analysis ${ }^{21}$ showed that, after follow-up of one year, the success rate was $89 \%$ and the use of mineral trioxide aggregate(MTA) gave better outcomes than other materials. Re-surgery is associated with poorer success rates, ranging from $35.7 \%$ in the pre-microsurgery era, ${ }^{22}$ to $44.7 \%$ when a microscope was used. ${ }^{16}$ In the latter study tooth survival was $74.5 \%$ and by comparison the survival rate for de novo cases in the same study was $89 \%$.

\section{TOOTH SURVIVAL}

Tooth survival has now been used as an indicator of success of root canal treatment. Although the goal of root canal treatment is to allow healing of the periradicular tissues this is not achievable in all cases. However, the tooth is symptomless and in function. As part of the prospective study by $\mathrm{Ng}$ et al. ${ }^{14}$ tooth survival was measured. After four years the cumulative tooth survival rate was 95.4\% for primary treatment and 95.3\% for secondary treatment. Post-operative factors relevant to survival of root filled teeth were:

- The presence of a cast restoration coronally (positive)

- Two proximal contacts (positive)

- Cast post and core (negative)

- Terminal tooth (negative).

Another study has shown high survival levels for root filled teeth, although these were better when specialists had treated the patient rather than general dental practitioners (98.1\% versus $89.7 \%) .{ }^{23}$ In 2010 , $\mathrm{Ng}$ et $a l .{ }^{24}$ published a systematic review of the literature on survival rates of teeth that had been root filled. Their findings are from 14 relevant studies, although it was difficult to compare findings because of disparate protocols. Survival at two to three years was $86 \%$ and at four to five years it was 93\%, but after eight to ten years it dropped to $87 \%$. They were able to place the influential factors in order of significance:

1. A full coverage coronal restoration after root canal treatment

2. Tooth has both mesial and distal proximal contacts

3. Tooth not acting as abutment for either a removable or fixed prosthesis

4. Tooth type, specifically non-molar teeth.

\section{THE ROLE OF THE CORONAL RESTORATION ON ROOT FILLED TEETH}

It is clear that there is a major role for the coronal restoration in protecting the weakened tooth structure of the root filled tooth and prevent re-infection from the oral microflora. Survival of root filled teeth has been shown to be high. A seminal paper by Salehrabi and Rotstein ${ }^{25}$ examined 1.46 million teeth in 1.12 million patients. Overall, 97\% of these teeth were retained after eight years following non-surgical root canal treatment. The majority (85\%) of the extracted teeth had no complete coronal restoration, which was significantly different from those teeth will full coverage. Aquilino and Caplan ${ }^{26}$ examined a random sample of 280 patients and 400 teeth. Teeth that were not crowned after root canal treatment were lost at a six times greater rate than those that had been crowned. Ploumaki et al. ${ }^{27}$ undertook a systematic review of the survival after six years of single crowns on root filled teeth. Teeth restored without a post showed a 94\% success rate but when a post was placed the success rates went down. Teeth with cast posts demonstrated a 93\% success rate, while with prefabricated posts the success rate was slightly higher at 94\%. The most common reason for failure was debonding of the restoration.

Coronal leakage as a cause of root canal treatment failure has been debated for some time. ${ }^{28,29}$ Poorly fitting restorations have been shown to be associated with an increased incidence of periradicular periodontitis. ${ }^{30-32}$ Gillan et al. $^{33}$ undertook a systematic review and meta-analysis on the significance of the coronal restoration compared with the quality of the root filling on the success of root canal treatment. They concluded that with adequate root canal treatment and coronal restoration the odds for success increased while less good clinical outcomes were seen when either the coronal restoration or the root canal treatment was judged to be inadequate. 


\section{IMPLANTS}

Failures with dental implants tend to occur either early, as a result of a failure to osseointegrate, or after osseointegration has been successful and, perhaps, after years of function. ${ }^{34,35}$ Early failure may be attributed to excessive surgical trauma, premature loading and infection and late failure as a result of prolonged marginal infection (periimplant mucositis and peri-implantitis). Periimplant mucositis is defined as reversible inflammation of the soft tissues around an implant and peri-implantitis is inflammation associated with loss of supporting bone. The latter has been detected in $28 \%$ of cases. ${ }^{36}$ Zitzmann et al..$^{37}$ in their thorough and candid review admit that the majority of studies of implants report success as retention of the implant only, despite marginal bone loss and the presence of mucositis. For example, bleeding on probing is often not measured. The criteria applied by Smith and Zarb ${ }^{3}$ for success are absence of clinical symptoms, no signs of inflammation and only limited bone loss marginally, not exceeding $0.2 \mathrm{~mm}$ after the first year.

In addition to biological failure there may be technical failures including fracture of the implant and loosening or fracture of the retainer. Pjetursson et al. ${ }^{38}$ conducted a systematic review of implant-supported fixed partial dentures and found that implant complications were seen in 39\% after five years. Survival rates for the implants were $95.4 \%$ and $92.8 \%$ after five and ten years respectively, and survival for the superstructure was 95\% after five years and $86.7 \%$ after ten years. Only $61.3 \%$ of patients had no complications after five years. In this review 21 studies matched the inclusion criteria. A more recent paper $^{39}$ includes 32 suitable studies in another systematic review. The implant survival rate in this larger cohort was $95.6 \%$ after five years and 93.1\% after ten years. There was a higher survival rate in rough surface implants compared with machined surface after five years at $97.2 \%$. The survival rates for the superstructure were $95.4 \%$ and $80.1 \%$ after five and ten years respectively. A slightly higher proportion (66.4\%) of implants were free of complications compared with the analysis in 2004 These studies ${ }^{38,39}$ include implants that have been used as fixed bridge abutments where it would be expected that more complex forces may act on the restoration. Jung et $a l^{40}$ have completed a recent systematic review of implantsupported single crowns. Forty studies were included and survival of the implants was $97.2 \%$ and $95.2 \%$ at five and ten years respectively. The crowns survival was $96.3 \%$ after five years and $89.4 \%$ after ten years. The

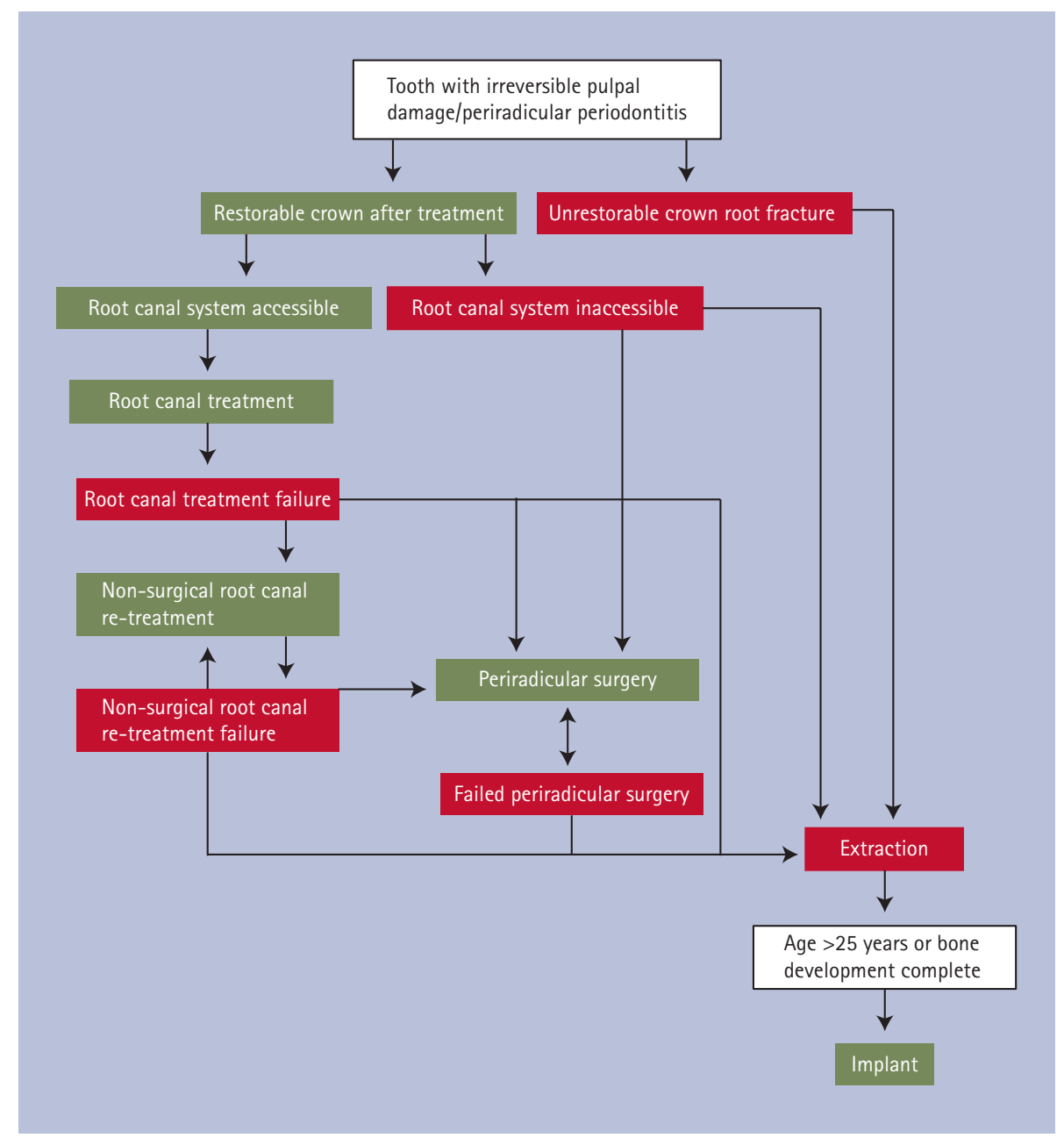

Fig. 1 Possible treatment pathways in the endodontic-implant continuum

authors concluded, however, that technical, biological and aesthetic complications were frequently encountered.

\section{IMPLANTS VERSUS ENDODONTIC TREATMENT}

The evidence of outcome studies of implant and endodontic treatment would suggest that both treatment options are valid and that preference depends on particular clinical considerations and the opinion of the clinician. ${ }^{41}$ In an editorial, Torabinejad ${ }^{42}$ compared the two treatment options as the difference between apples and pears. There were indications for both and he was clear that a saveable tooth should not be extracted and replaced by an implant. The essence of decision-making should be based upon proper treatment planning. Further comparisons between the two treatment options have been made. Torabinejad et $a l .{ }^{43}$ undertook a systematic review and found that both treatments had a high success, which was better long-term than fixed partial dentures. It was difficult for the authors to make direct comparisons among studies because success criteria were very different. Interestingly, extraction of teeth without replacement was shown to produce poorer psychological outcomes. Hannahan and Eleazer ${ }^{44}$ undertook a direct comparison between a cohort of patients that had received root canal treatment and another that received implants. The success rate was the same for both treatments after an average of 36 months but implants required more post-operative treatments than root canal treated teeth (12.4\% versus $1.3 \%$ ). In a more recent paper, Vozza et al. ${ }^{45}$ undertook a small cohort study over eight years and found that outcomes for the two treatments was essentially the same.

In summary the decision to undertake root canal treatment or implant therapy cannot be based exclusively on outcome because both treatments are based on differing biological and diagnostic principles, failure patterns and patient preferences. ${ }^{46}$ Figure 1 provides an algorithm for the endodonticimplant continuum.

\section{The effect of systemic disease and treatments on prognosis}

A number of systemic conditions have been cited as potential contraindications to root canal and implant treatment and these should be considered carefully during treatment planning. 


\section{Endodontics}

There are few health contraindications to both non-surgical and surgical root canal treatment. The principal health issue is diabetes mellitus, where it has been shown that success rates are decreased in patients with a pre-existing periapical radiolucency. ${ }^{47}$ Several papers have shown there is no difference in success rates of root canal treatment for patients infected with HIV and those without the disease. ${ }^{48,49}$ Patients with nonspecific immune system disorders, which might include diabetes, were 8.85 times more likely to have a less successful outcome for root canal treatment than controls. ${ }^{50}$ Pregnancy is not a contraindication to root canal treatment but some believe the treatment should be carried out in the second trimester. However, there may be issues undertaking radiography for these patients. Patients with a history of hypertension and bleeding disorders can be subjected to root canal treatment, including surgical treatment, but of course care must be taken to manage these patients appropriately.

\section{Implants}

Zitzmann et al. ${ }^{37}$ have outlined the contraindications for implant placement. They considered three medical conditions as absolute, although temporary, contraindications. These were acute infectious disease, pregnancy and cancer chemotherapy. An absolute contraindication is severe psychosis where a patient with a successful implant may demand removal because of a distorted view of the implant as a foreign body. Implant placement for patients on systemic bisphosphonate therapy for bone tumours and osteoporosis must be undertaken with caution because of the risk of bisphosphonate-induced osteo-chemonecrosis. Diabetes is a relative complication and is not a contraindication provided co-morbidities, such as oral hygiene and cigarette smoking are addressed..$^{51,52}$

Implants are ideal for replacing teeth that are lost through trauma. This should only be considered when cranial growth is complete and adjacent teeth have erupted. It is recommended that single tooth implants in the anterior region are not placed before the age of 25 years but hand-wrist radiographs can be utilised to evaluate the end of skeletal growth. ${ }^{37,53,54}$

\section{Local factors}

\section{Periodontal disease}

Periodontal disease may be considered a risk factor for the provision of both root canal treatment and implants. Root canal treatment is complicated in the presence of combined disease of both pulpal and periodontal origin. Good diagnostic skills are required to ascertain the principal cause of the lesion and it is recognised that treatment of endodontic disease is more predictable than the treatment for periodontal disease. ${ }^{55}$ It has been shown that root canal treatment of teeth with a primary periodontal lesion and secondary endodontic lesion improves the periodontal attachment ${ }^{56}$ and this can be further enhanced by guided tissue regeneration. ${ }^{57}$ Thus, periodontal disease is not a contraindication to root canal treatment.

The evidence for the success of implants placed in patients with periodontal disease is rather weak but overall there is some evidence that there may be more implant loss in patients with periodontitis. ${ }^{58,59} \mathrm{~A}$ more recent clinical study compared implant placement in a cohort of patients with and without a history of periodontal disease and found no difference in success after 24 months, but sulcus bleeding index scores were increased in the periodontitis group. ${ }^{60} \mathrm{It}$ has been emphasised that the elimination of residual pockets is essential before implant placement. ${ }^{61}$ Reassuringly, the presence of generalised aggressive periodontitis does not seem to be a contraindication to dental implant placement. ${ }^{62}$

When deciding on the provision of any treatment plan it is important to understand the possible sequelae and the patient should be informed. The placement of implants is not without subsequent difficulties, as already discussed. However, failure of these prostheses is in most cases a result of inflammation around the implant, conditions known as peri-implant mucositis and periimplantitis. A number of systematic reviews of these conditions have been published. ${ }^{63,64}$ Peri-implant mucositis affects between $39.4-80 \%$ of patients with implants. It is regarded as the equivalent of gingivitis in natural teeth and is caused by the presence of dental plaque. If left untreated it progresses to peri-implantitis. A thorough systematic review analysing 504 studies, of which nine were suitable, showed $18.8 \%$ of patients had evidence of peri-implantitis affecting $9.6 \%$ of the implants. The prevalence of mucositis was higher, with $63.4 \%$ of patients and 30.7\% of implants. The use of supportive periodontal therapy reduced the rate of occurrence of peri-implant disease. ${ }^{64}$

The presence of periapical disease does not compromise the success of an implant placed immediately after extraction if the socket is carefully debrided ${ }^{65}$

\section{Quality of the coronal tooth structure}

The amount and quality of the remaining tooth structure must be assessed before a decision is made to undertake root canal treatment. Bandlish et $a l .{ }^{66}$ provided the tooth restorability index, where the crown of the tooth is distributed into sextants and the amount of tooth structure remaining after preparation is given a score from 0-3. Thus the maximum score that can be attributed is 18 . There are no studies on the minimum score that will predictably allow restoration and restore function.

Vertical root fractures are, in general, a contraindication to root canal treatment; especially those extending down into the middle and apical part of the root. ${ }^{67}$ Very often these generate a localised periodontal pocket along their length with subsequent loss of marginal bone. It is important to check for isolated pockets in teeth being assessed for root canal treatment.

Protection of the remaining tooth structure in the restoration of root filled teeth is crucial, with provision of a ferrule at the margins of the restoration. ${ }^{68-70}$

\section{Quality and quantity of alveolar bone}

The amount of bone available to place an implant is important although predictable strategies have been developed to enhance bone support through guided tissue regeneration and bone grafting. A number of classifications of bone characteristics have been developed but these are not used consistently. ${ }^{71}$ However, subjective assessment of bone quality is possible and implants placed in bone judged to be of good quality performed better than those placed in moderate or poor quality bone. ${ }^{72}$

\section{Habits}

Habits must be taken into account when planning for root canal treatment and implants. Smoking has an adverse effect on both root canal treatment ${ }^{73,74}$ and implants ${ }^{52,74-76}$ and efforts should be made to encourage patients to quit. ${ }^{77}$

Patients with bruxism must be assessed very carefully. A systematic review of the implant literature suggest that bruxism is unlikely to be a risk factor for biological complications associated with implants but it may be a risk factor for mechanical failures. ${ }^{78}$ Bone loss as a consequence of implant overload is only evident in cases with preexisting peri-implant inflammation. ${ }^{79}$

There is little in the literature regarding the relationship between occlusal loading and endodontic outcome. While it is clear that protection of the coronal tooth structure is paramount following root canal treatment to avoid catastrophic fracture of the crown and vertical root fractures, the relationship between healing of periradicular periodontitis and occlusal load is not well understood. A case report suggests there may be a link. ${ }^{80}$ 


\section{Aesthetics}

Aesthetics must be considered in the planning of root canal treatment and implants. The presence of a tooth allows retention of the gingival architecture and if the natural crown of the tooth is badly damaged then contemporary bonding and crown techniques provide a good result. In those cases where the natural crown is more or less intact and the tooth is discoloured non-vital bleaching techniques are reliable and relatively non-invasive. ${ }^{81}$

Achieving good aesthetics for anterior implant retained prostheses, is more problematical, and careful planning is necessary. ${ }^{82}$ Belser et al. $^{83}$ found that early placement of implants in the anterior maxilla was a predictable treatment from the aesthetic perspective. In a 12 to 15 year retrospective study of 31 implant-supported crowns, Misje et al.$^{84}$ found that despite a high number of prosthetic complications the patients were satisfied with the aesthetic outcome. Although a number of indices for assessing aesthetics have been developed, overall standardisation of these indices is required. ${ }^{85}$

\section{Patient factors}

A number of patient factors not related to general health issues have to be considered when planning treatment for root canal treatment or implants. Many of these are common to both treatments, including dental anxiety, lack of patient cooperation, inability to be reclined, sensitive gag reflex and trismus, preventing access to the tooth or surgical site.

In addition, financial constraints should be discussed. Pennington et al. ${ }^{86}$ evaluated the cost-effectiveness of treatment using a Markov model. They concluded that root canal treatment and non-surgical root canal retreatment were cost effective while surgical retreatment was not. It was cheaper per year to extend the life of the crown by replacement with a single tooth implant if root canal treatment failed. Implants are considered to be more cost-effective than short-span fullpreparation fixed bridges. ${ }^{87}$ Another study ${ }^{88}$ compared various treatment alternatives based upon the American Dental Association survey of dental fees. They concluded that endodontic microsurgery was more cost-effective for a failed root canal treated molar compared with an implant-retained restoration.

\section{Quality of life}

One of the principal goals of advanced restorative dental treatment, including endodontics and implant placement, is to improve the quality of life for patients. A survey of patients conducted by Gatten et al. ${ }^{89}$ showed a high degree of satisfaction with both endodontic and implant treatment. Factors considered by patients to be important were overall general health, costs, perception of treatment and its outcomes and subsequent dental follow-up. The patients were content with the treatment they had received but they were anxious to save their natural dentition whenever possible.

Good masticatory function also contributes to quality of life. One study has shown that endodontically treated natural teeth may provide more effective chewing than implant retained restorations. ${ }^{90}$

\section{The influence of the dentist}

The provision of a treatment plan for a tooth is of course influenced by the dental surgeon's training and prejudices. Two studies from North America demonstrate that there is a dichotomy in the preference between an implant and root canal treatment. In one study from Canada ${ }^{91}$ there was an increasing preference for an implant-supported restoration compared with root canal retreatment. Conversely, another study ${ }^{92}$ found that there was not a shift towards implant treatment compared with endodontic treatment, despite a perception that implant treatment produced a better outcome.

\section{CONCLUSIONS}

Patients now face a number of choices regarding the treatment of individual teeth. A tooth can be retained with root canal treatment and subsequent restoration or may be extracted and not replaced, or replaced with a bridge, a removable denture or an implant. Each case must be regarded as unique and the choices outlined to the patient. There is no doubt that all these treatments have a place and no particular option should be regarded as the best. Dentists have a duty to provide a comprehensive review of the benefits and risks for each option and to ensure that the patient's needs are addressed with the goal of improving oral and general health.

Iqbal M K, Kim S. A review of factors influencing treatment planning decisions of single-tooth implants versus preserving natural teeth with nonsurgical endodontic therapy. J Endod 2008; 34: 519-529.

2. Albrektsson T, Zarb G, Worthington P, Eriksson A R. The long-term efficacy of currently used dental implants: A review and proposed criteria of success. Int J Oral Max Imp/ 1986; 1: 11-25.

3. Smith D E, Zarb G A. Criteria for success of osseointegrated endosseous implants. J Prosthet Dent 1989; 62: 567-572.

4. Strindberg L. The dependence of the results of pulp therapy on certain factors. An analytic study based on radiographic and clinical follow up examinations. Acta Odontol Scand 1956; 14(Suppl 21): 1-175.

5. Rud J, Andreasen J 0. A study of failures after endodontic surgery by radiographic, histologic and stereomicroscopic methods. Int J Oral Surg 1972; 1: $311-328$.

6. Molven O, Halse A, Grung B. Observer strategy and the radiographic classification of healing after endodontic surgery. Int J Oral Max Surg 1987; 16: 432-439.

7. Orstavik D. Reliability of the periapical index scoring system. Scand J Dent Res 1988; 96: 108-111.

8. Van Nieuwenhuysen J P, Aouar M, D'Hoore W. Retreatment or radiographic monitoring in endodontics. Int Endod J 1994; 27: 75-81.

9. Ng Y, Mann V, Rahbaran S, Lewsey J, Gulabivala K. Outcome of primary root canal treatment: Systematic review of the literature- part 1. effects of study characteristics on probability of success. Int Endod J 2007; 40: 921-939.

10. Ng Y, Mann V, Rahbaran S, Lewsey J, Gulabivala K. Outcome of primary root canal treatment: Systematic review of the literature- part 2. influence of clinical factors. Int Endod J 2008; 41: 6-31.

11. Ng Y-L, Mann V, Gulabivala K. Outcome of secondary root canal treatment: a systematic review of the literature. Int Endod J 2008 41: 1026-46.

12. Fleming $\mathrm{CH}$, Litaker $M S$, Alley $L$ W, Eleazer $P$ D. Comparison of classic endodontic techniques versus contemporary techniques on endodontic treatment success. J Endod 2010; 36: 414-418.

13. Ng Y, Mann V, Gulabivala K. A prospective study of the factors affecting outcomes of nonsurgical root canal treatment: Part 1: Periapical health. Int Endod J 2011; 44: 583-609.

14. Ng Y, Mann V, Gulabivala K. A prospective study of the factors affecting outcomes of non-surgical root canal treatment: Part 2: Tooth survival. Int Endod J 2011; 44: 610-625.

15. Rubenstein R A, Kim S. Long-term follow-up of cases considered healed after one year after apical microsurgery. J Endod 2002; 28: 378-383.

16. Saunders W P. A prospective clinical study of periradicular surgery using mineral trioxide aggregate as a root-end filling J Endod 2008; 34: 660-665.

17. Taschieri S, Del Fabbro M, Restori T, Weinstein R. Endodontic periradicular surgery: A prospective clinical study. Br J Oral Maxilofac Surg 2007; 45: 242-244.

18. Chong B S, Pitt Ford T R, Hudson MB. A prospective clinical study of mineral trioxide aggregate and IRM when used as root filling materials in endodontic surgery. Int Endod J 2003; 36: 520-526.

19. Setzer F C, Shah S B, Kohli M R, Karabucak B, Kim S. Outcome of endodontic surgery: A meta-analysis of the literature- part 1: Comparison of traditional root-end surgery and endodontic microsurgery. J Endod 2010; 36: 1757-1765.

20. Setzer F C, Kohli M R, Shah S B, Karabucak B, Kim S. Outcome of endodontic surgery: A meta-analysis of the literature- part 2: Comparison of endodontic microsurgical techniques with and without the use of higher magnification. J Endod 2012; 38: 1-10.

21. Tsesis I, Rosen E, Taschieri S, Telishevsky Strauss Y, Ceresoli V, Del Fabbro M. Outcomes of surgical endodontic treatment performed by a modern technique: An updated meta-analysis of the literature. J Endod 2013; 39: 332-339.

22. Peterson J, Gutmann J L. The outcome of endodontic resurgery: a systematic review. Int Endod J 2001; 34: 169-175.

23. Alley B S, Kitchens G G, Alley L W, Eleazer P D. A comparison of survival of teeth following endodontic treatment performed by general dentists or by specialists. Oral Surg Oral Med Oral Pathol Oral Radiol Endod 2004; 98: 115-118.

24. Ng Y L, Mann V, Gulabivala K. Tooth survival following non-surgical root canal treatment: a systematic review of the literature. Int Endod J 2010; 43: 171-189.

25. Salehrabi R, Rotstein I. Endodontic treatment outcomes in a large patient population in the USA: an epidemiological study. J Endod 2004; 30: 846-850.

26. Aquilino S A, Caplan D J. Relationship between crown placement and the survival of endodontically treated teeth. J Prosthet Dent 2002; 87: 256-263.

27. Ploumaki A, Bilkhair A, Tuna T, Stampf S, Strub $J$ R. Success rates of prosthetic restorations on endodontically treated teeth; a systematic review after 6 years. J Oral Rehabil 2013; 40: 618-630.

28. Saunders W P, Saunders E M. The root filling and restoration continuum-prevention of long-term endodontic failures. Alpha Omegan 1997; 90: 40-46 29. Ricucci D, Siqueira J F Jr. Recurrent apical 
periodontitis and late endodontic treatment failure related to coronal leakage: a case report. J Endod 2011; 37: 1171-1175.

30. Hommez G M, Coppens C R, de Moor R J. Periapical health related to the quality of coronal restorations and root fillings. Int Endod J 2002; 35: 680-689.

31. Iqbal M K, Johansson A A, Akeel R F, Bergenholtz A, Omar R. A retrospective analysis of factors associated with the periapical status of restored endodontically treated teeth. Int J Prosthodont 2003; 16: 31-38.

32. Ray H A, Trope M. Periapical status of endodontically treated teeth in relation to the technical quality of the root filling and coronal restoration. Int Endod 1995; 28: 12-18.

33. Gillen B M, Looney S W, Gu L et al. Impact of the quality of coronal restoration versus the quality of root canal fillings on success of root canal treatment: A systematic review and meta-analysis. J Endod 2011; 37: 895-902.

34. Esposito M, Hirsch J, Lekholm U, Thomsen P. Biological factors contributing to failures of osseointegrated oral implants: (II). etiopathogenesis. Eur J Oral Sci 1998; 106: 721-764.

35. Esposito M, Hirsch J, Lekholm U, Thomsen P. Biological factors contributing to failures of osseointegrated ora implants. (I). success criteria and epidemiology. Eur J Oral Sci 1998; 106: 527-551.

36. Zitzmann N U, Berglundh T. Definition and prevalence of peri-implant diseases. J Clin Periodontol 2008 - 35(Suppl 8): 286-291.

37. Zitzmann N U, Krastl G, Hecker H, Walter C, Weiger R. Endodontics or implants? A review of decisive criteria and guidelines for single tooth restorations and full arch reconstructions. Int Endod J 2009; 42: 757-774.

38. Pjetursson B E, Tan K, Lang N P, Brägger U, Egger M, Zwahlen M. A systematic review of the survival and complication rates of fixed partial dentures (FPDs) after an observation period of at least 5 years: I. implant-supported FPDs. Clin Oral Implants Res 2004; 15: 625-642.

39. Pjetursson B E, Thoma $D$, Jung $R$, Zwahlen $M$, Zembic A. A systematic review of the survival and complication rates of implant-supported fixed dental prostheses (FDPs) after a mean observation period of at least 5 years. Clin Oral Implants Res 2012; 23(Suppl 6): 22-38.

40. Jung $R E$, Zembic A, Pjetursson B E, Zwahlen $M$, Thoma D S. Systematic review of the survival rate and the incidence of biological, technical, and aesthetic complications of single crowns on implants reported in longitudinal studies with a mean follow-up of 5 years. Clin Oral Implants Res 2012; 23(Suppl 6): 2-21.

41. Blicher B, Baker D, Lin J. Endosseous implants versus nonsurgical root canal therapy: A systematic review of the literature. Gen Dent 2008; 56: 576-580.

42. Torabinejad M. Apples and oranges. J Endod 2003; 29: $541-542$.

43. Torabinejad $\mathrm{M}$, Anderson P, Bader J et al. Outcomes of root canal treatment and restoration, implantsupported single crowns, fixed partial dentures and extraction without replacement: a systematic review. J Prosthet Dent 2007; 98: 285-311.

44. Hannahan J P, Eleazer P D. Comparison of success of implants versus endodontically treated teeth. J Endod 2008; 34: 1302-1305.

45. Vozza I, Barone A, Quaranta M, De Paolis G, Covani U, Quatanta A. A comparison between endodontics and implantology: An 8-year retrospective study. Clin Implant Dent Relat Res 2013; 15: 29-36.

46. Elemam R F, Pretty I. Comparison of the success rate of endodontic treatment and implant treatment. ISRN Dent 2011; 2011: 1-8.

47. Fouad A F, Burleson J. The effect of diabetes mellitus on endodontic treatment outcome: Data from an electronic patient record. J Am Dent Assoc 2003; 134: 43-51.

48. Cooper H. Root canal treatment on patients with HIV infection. Int Endod 1993; 26: 369-371.

49. Alley B S, Buchanan T H, Eleazer P D. Comparison of the success of root canal therapy in HIV/AIDS patients and non-infected controls. Gen Dent 2008; 56: 155-157.

50. Marending $\mathrm{M}$, Peters $\mathrm{O}$ A, Zehnder M. Factors affecting the outcome of orthograde root canal therapy in a general dentistry hospital practice. Oral Surg Oral Med Oral Pathol Oral Radiol Endod 2005: 99: 119-124.

51. Marchand F, Raskin A, Dionnes-Hornes A et al. Dental implants and diabetes: conditions for success. Diabetes Metab 2012; 38: 14-19.

52. Chen H, Liu N, Xu X, Qu X, Lu E. Smoking, radiotherapy, diabetes and osteoporosis as risk factors for dental implant failure: A meta-analysis. PLOS ONE 2013; 8: e71955.

53. Schwartz-Arad D, Bichacho N. Effect of age on single implant submersion rate in the central maxillary incisor region: a long-term retrospective study. Clin Implant Dent Relat Res 2013.

54. Op Heij D G, Opdebeeck H, Van Steenberghe D, Quirynen M. Age as compromising factor for implant insertion. Periodontol 2000 2003; 33: 172-184.

55. Rotstein I, Simon J H S. Diagnosis, prognosis and decision-making in the treatment of combined periodontal-endodontic lesions. Periodontol 2000 2004; 34: 165-203.

56. Kwon E, Cho Y, Lee J, Kim S, Choi J. Endodontic treatment enhances the regenerative potential of teeth with advanced periodontal disease with secondary endodontic involvement. J Periodontal Implant Sci 2013; 43: 136-140.

57. Oh S, Fouad A F, Park S. Treatment strategy for guided tissue regeneration in combined endodonticperiodontal lesions: Case report and review. J Endod 2009: 35: 1331-1336.

58. Ong C T, Ivanovski S, Needleman I G et al. Systematic review of implant outcomes in treated periodontitis subjects. J Clin Periodontol 2008; 35: 438-462.

59. Safii S H, Palmer R M, Wilson R F. Risk of implant failure and marginal bone loss in subjects with a history of periodontitis: A systematic review and meta-analysis. Clin Implant Dent Relat Res 2010; 12: 165-174.

60. Jiang B O, Lan J, Huang H Y et al. A clinical study on the effectiveness of implant supported dental restoration in patients with chronic periodontal diseases. Int J Oral Maxillofac Surg 2013; 42: 256-259.

61. Cho-Yan Lee J, Mattheos N, Nixon K C, Ivanovski S. Residual periodontal pockets are a risk indicator for peri-implantitis in patients treated for periodontitis. Clin Oral Implants Res 2012; 23: 325-333.

62. Kim K, Sung H. Outcomes of dental implant treatment in patients with generalized aggressive periodontitis: A systematic review. J Adv Prosthodont 2012; 4: 210-217.

63. Zeza B, Pilloni A. Peri-implant mucositis treatments in humans: a systematic review. Ann Stomatol (Roma) 2012; 111: 83-89.

64. Atieh M A, Alsabeeha N H, Faggion C M, Duncan $\mathrm{W} J$. The frequency of peri-implant disease: a systematic review and meta analysis. J Periodontol 2013; 84: 1586-1598.

65. Truninger T C, Philipp A O, Siegenthaler D W, Roos $\mathrm{M}$, Hämmerle $\mathrm{C} H$, Jung $\mathrm{R} \mathrm{E}$. A prospective, controlled clinical trial evaluating the clinical and radiological outcome after 3 years of immediately placed implants in sockets exhibiting periapical pathology. Clin Oral Implants Res 2011; 22: 20-27.

66. Bandlish R B, McDonald A V, Setchell D J. Assessment of the amount of remaining coronal dentine in roottreated teeth. J Dent 2006; 34: 699-708.

67. Tsesis I, Rosen E, Tamse A, Taschieri S, Kfir A. Diagnosis of vertical root fractures in endodontically treated teeth based on clinical and radiographic indices: a systematic review. J Endod 2010; 36: 1455-1458.

68. Sorensen J A, Martinoff J T. Endodontically treated teeth as abutments. J Prosthet Dent 1985; 53 : 631-636.

69. Stankiewicz N, Wilson P. The ferrule effect. Dent Update 2008; 35: 222-224, 227-228.

70. Juloski J, Radovic I, Goracci C, Vulicevic Z R, Ferrari M. Ferrule effect: A literature review. J Endod 2012; 38: $11-19$.

71. Ribeiro-Rotta R F, Lindh C, Pereira A C, Rohlin $M$. Ambiguity in bone tissue characteristics as presented in studies on dental implant planning and placement: A systematic review. Clin Oral Implants Res 2011; 22: 789-801.

72. Holahan C M, Wiens J L, Weaver A, Assad D, Koka S. Relationship between systemic bone mineral density and local bone quality as effectors of dental implant survival. Clin Implant Dent Relat Res 2011; 13: 29-33.

73. López-López J, Jané-Salas E, Martín-González J et al. Tobacco smoking and radiographic periapical status: a retrospective case-control study. J Endod 2012; 38: $584-588$.

74. Doyle S L, Hodges J S, Pesun I J, Baisden M K, Bowles W R. Factors affecting outcomes for single-tooth implants and endodontic restorations. J Endod 2007 33: 399-402.

75. Bain C A, Moy P K. The association between the failure of dental implants and cigarette smoking. Int J Oral Maxillofac Implants 1993; 8: 609-615.

76. Anner R, Grossmann Y, Anner Y, Levin L. Smoking, diabetes mellitus, periodontitis, and supportive periodontal treatment as factors associated with dental implant survival: A long-term retrospective evaluation of patients followed for up to 10 years. Implant Dent 2010; 19: 57-64.

77. Bain C A. Smoking and implant failure- benefits of a smoking cessation protocol. Int J Oral Maxillofac Implants 1996; 11: 756-759.

78. Manfredini D, Poggio C E, Lobbezoo F. Is bruxism a risk factor for dental implants? A systematic review of the literature. Clin Implant Dent Relat Res 2012, [epub ahead of print].

79. Naert I, Duyck J, Vandamme K. Occlusal overload and bone/implant loss. Clin Oral Implants Res 2012; 23(Suppl 6): 95-107.

80. Harn W, Chen M, Chen Y M, Liu J, Chung C. Effect of occlusal trauma on healing of periapical pathoses: Report of two cases. Int Endod J 2001; 34: 554-561.

81. Attin T, Paqué F, Ajam F, Lennon Á M. Review of the current status of tooth whitening with the walking bleach technique. Int Endod J 2003: 36: 313-329.

82. Délben J A, Goiato M C, Gennari-Filho H, Assunção W G, Dos Santos D M. Esthetics in implantsupported prostheses: a literature review. J Oral Implantol 2012; 38: 718-722.

83. Belser U C, Grütter L, Vailati F, Bornstein M M, Weber $H_{1}$ Buser D. Outcome evaluation of early placed maxillary anterior single-tooth implants using objective esthetic criteria: A cross-sectional, retrospective study in 45 patients with a 2-to 4-year follow-up using pink and white esthetic scores. J Periodontol 2009; 80: 140-151.

84. Misje K, Bjørnland T, Saxegaard E, Jensen J L, Treatment outcome of dental implants in the esthetic zone: a 12-to 15-year retrospective study. Int J Prosthodont 2013; 26: 365-369

85. Lang N P, Zitzmann N U. Clinical research in implant dentistry: Evaluation of implant-supported restorations, aesthetic and patient-reported outcomes. J Clin Periodontol 2012; 39(Suppl 12): 133-138.

86. Pennington M W, Vernazza C R, Shackley P, Armstrong $N$ T, Whitworth J M, Steele J G. Evaluation of cost effectiveness of root canal treatment using conventional approaches versus replacement with an implant. Int Endod J 2009; 42: 874-883.

87. Scheuber S, Hicklin S, Brägger U. Implants versus shortspan fixed bridges: Survival, complications, patients' benefits. A systematic review on economic aspects. Clin Oral Implants Res 2012; 23(Suppl 6): 50-62.

88. Kim S G, Solomon C. Cost-effectiveness of endodontic molar retreatment compared with fixed partial dentures and single-tooth implant alternatives. J Endod 2011; 37: 321-325.

89. Gatten D L, Riedy C A, Hong S K, Johnson J D, Cohenca N. Quality of life of endodontically treated versus implant treated patients: A university-based qualitative research study. J Endod 2011; 37: 903-909.

90. Woodmansey K F, Ayik M, Buschang P H, White $C A$, He J. Differences in masticatory function in patients with endodonticall treated teeth and ingle-implant-supported prostheses: a pilot study. J Endod 2009; 35: 10-14.

91. Azarpazhooh A, Dao T, Figueiredo R, Krahn M, Friedman S. A survey of dentists' prefences for the treatment of teeth with apical peridiodontitis. J Endod 2013; 39: 1226-1233.

92. Stockhausen R, Aseltine R Jr, Matthews J G, Kaufman B. The perceived prognosis of endodontic treatment and implant therapy among dental practitioners. Oral Surg Oral Med Oral Pathol Oral Radiol Endod 2011; 111: e42-47. 